\title{
Hydrogen Production Using Reduced-Iron Nanoparticles by Laser Ablation in Liquids
}

\author{
Takehiro Okada, ${ }^{1}$ Taku Saiki, ${ }^{1}$ Seiji Taniguchi, ${ }^{2}$ Tsuyoshi Ueda, ${ }^{1}$ Kazuhiro Nakamura, \\ Yusuke Nishikawa, ${ }^{1}$ and Yukio Iida ${ }^{1}$ \\ ${ }^{1}$ Department of Electrical and Electronic Engineering, Faculty of Engineering Science, Kansai University, 3-3-35 Yamate-cho, \\ Suita, Osaka 564-8680, Japan \\ ${ }^{2}$ Institute for Laser Technology, 1-8-4 Utsubo-honmachi, Nishi-ku, Osaka 550-0004, Japan \\ Correspondence should be addressed to Takehiro Okada; gd50022@live.jp
}

Received 28 December 2012; Accepted 3 February 2013

Academic Editors: S. S. Kalligeros and Z. Oktay

Copyright (c) 2013 Takehiro Okada et al. This is an open access article distributed under the Creative Commons Attribution License, which permits unrestricted use, distribution, and reproduction in any medium, provided the original work is properly cited.

\begin{abstract}
A recyclable energy cycle using a pulsed laser and base-metal nanoparticles is proposed. In this energy cycle, iron nanoparticles reduced from iron oxides by laser ablation in liquid are used for hydrogen generation. The laser energy can be stored in the basemetal nanoparticles as the difference between the chemical energies of iron oxide and iron. According to the results of an experiment on hydrogen production using the reduced iron nanoparticles, the reaction efficiency of the hydrogen generation at a temperature of $673 \mathrm{~K}$ was more than $94 \%$ for the ideal amount of generated hydrogen.
\end{abstract}

\section{Introduction}

It has been expected that the application of hydrogen, produced by using clean, renewable energy, such as solar power, will solve the problem of global warming and depletion of fossil fuels. Many researches on hydrogen production have been conducted around the world [1-6]. Among them, the researches on generating hydrogen on the basis of the reaction of a metal with water are particularly interesting for the following reason: the method used to produce the hydrogen is very simple and low cost. Magnesium [2,3], aluminum [4], and iron $[5,6]$ have already been used to generate hydrogen. Iron has the advantage of high safety in regard to handling because it hardly reacts with water at low temperature when compared to magnesium and aluminum. In some researches, metal nanoparticles were used to generate hydrogen [6]. It is important to increase the surface area of the metal particles by "micronizing" the particles to improve the reaction efficiency of metals with water. Moreover, the generated metal oxides should return to metals by reducing to realize an energy cycle.

The metal oxides can be reduced to the metal and broken into nanoparticles by using pulsed-laser ablation in liquid [713]. This process consists of three steps: first, the metal oxide is heated to a high temperature in a short time by irradiating laser pulses onto a metal-oxide powder in the liquid. Second, after the laser pulse is irradiated, metal oxides are evaporated, and metals are atomized; the separated oxygen is rearranged as the outer shell of the metal particles. Third, after the metals are separated from their oxides near the irradiation point of the laser pulse, the metal atoms are aggregated by cooling, and nanoparticles are produced rapidly. As physical mechanisms, namely, the ablation mechanism of the metal oxide in the liquid, coulomb explosions $[14,15]$ and thermal ablation have been proposed. With this pulsed-laser ablation in liquid, high reduction efficiency is obtained because the liquid also works as a coolant. Recombination between oxygen and metal particles is prevented because liquid cools the generated metal particles rapidly. Furthermore, it has the advantage that it can create nanoparticles with low cost easily because the produced particles can be collected easily.

As shown in Figure 1, an energy cycle produced by using a pulsed laser and base-metal nanoparticles has been proposed [16]. In general, the metal nanoparticles generated by pulsedlaser ablation in liquid have been applied only to thin-film coatings owing to the high cost of the laser oscillator. As shown in Figure 2, many kinds of solar-pumped lasers have 


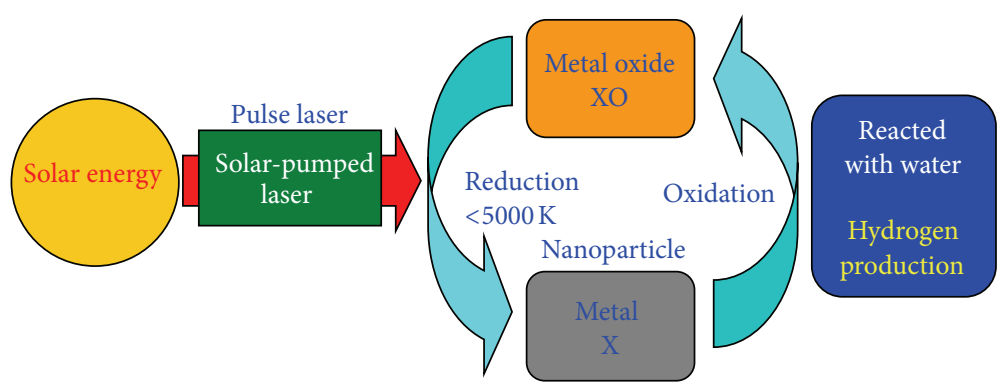

FIGURE 1: Proposed energy cycle using solar energy.

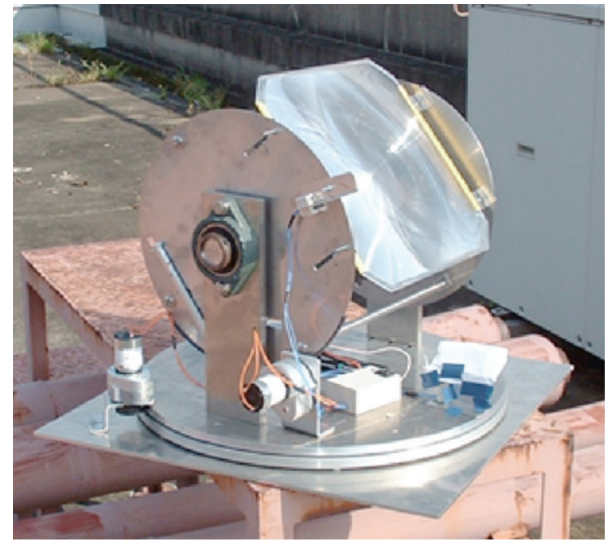

FIGURE 2: Small-scale solar-pumped laser.

been developed [16-18]. They can directly convert from incoherent solar light to laser light. And they have an advantage in terms of consuming almost only solar power when generating a laser beam. Now, optical-optical conversion efficiency of solar-pumped lasers has been improved to almost $60 \%$ (i.e., from solar light to laser light) by improvements in optical technology [18]. Moreover, these lasers can generate laser pulses with high energy and high peak intensity. Accordingly, they can be used for reducing metal oxide and fabricating metal nanoparticles in our proposed energy cycle. The production of hydrogen by using reduced metal powder with nanometer-order diameters by continuous wave (CW) or pulsed laser has not been reported until now except for our report. In this study, iron nanoparticles were synthesized by reduction by pulsed laser in liquids, and the reaction efficiency of producing hydrogen by reacting the fabricated metal nanoparticles with vaporized water was experimentally investigated.

\section{Experimental Setup}

2.1. Laser Ablation in Liquids. The required energy for reducing iron metal oxides is determined as follows. $\mathrm{Fe}_{2} \mathrm{O}_{3}, \mathrm{Fe}_{3} \mathrm{O}_{4}$, and $\mathrm{FeO}$ are generally known as "iron oxides." According to crystal structure, there are many types. The chemical formula for the reduction of $\mathrm{Fe}_{2} \mathrm{O}_{3}$ is given as

$$
\frac{1}{2} \mathrm{Fe}_{2} \mathrm{O}_{3}(\mathrm{~s}) \longrightarrow \mathrm{Fe}(\mathrm{s})+\frac{3}{4} \mathrm{O}_{2}(\mathrm{~g}), \quad \Delta H=412 \mathrm{~kJ} / \mathrm{mol} .
$$

The chemical formula for the reduction of $\mathrm{Fe}_{3} \mathrm{O}_{4}$ is given as

$$
\frac{1}{3} \mathrm{Fe}_{3} \mathrm{O}_{4}(\mathrm{~s}) \longrightarrow \mathrm{Fe}(\mathrm{s})+\frac{2}{3} \mathrm{O}_{2}(\mathrm{~g}), \quad \Delta H=373 \mathrm{~kJ} / \mathrm{mol} .
$$

Here, $\Delta H$ is the enthalpy energy required for reducing unit mol Fe. The basic enthalpy energy required for reducing $\mathrm{Fe}_{2} \mathrm{O}_{3}$ to $\mathrm{Fe}_{3} \mathrm{O}_{4}$ is $39 / 2 \mathrm{~kJ}$ per unit mol of $\mathrm{Fe}_{3} \mathrm{O}_{4}$. These chemical reactions are all endothermic reactions. It is clear from (1) and (2) that the required chemical energy to separate the iron and oxygen atoms is large. As for the temperature required to change the $\mathrm{Fe}_{2} \mathrm{O}_{3}$ to $\mathrm{Fe}_{3} \mathrm{O}_{4}, 2100 \mathrm{~K}$ is required, once the temperature is reduced to $1700 \mathrm{~K}$. After $\mathrm{Fe}_{2} \mathrm{O}_{3}$ is changed to $\mathrm{Fe}_{3} \mathrm{O}_{4}$, the $\mathrm{Fe}_{3} \mathrm{O}_{4}$ must be heated to $1900 \mathrm{~K}$ to reduce it to $\mathrm{FeO}$. Iron can then be obtained after heating the $\mathrm{FeO}$ to a higher temperature still. It is generally considered that $\mathrm{FeO}$ did not exist to change $\mathrm{Fe}_{3} \mathrm{O}_{4}$ and iron by disproportionate ambient temperature. After $\mathrm{FeO}$ particles are generated, they will change to iron and $\mathrm{Fe}_{3} \mathrm{O}_{4}$ particles due to the disproportionate reaction below $850 \mathrm{~K}$.

The following metal-oxide powders were used to reduce and produce metal nanoparticles: $\mathrm{Fe}_{2} \mathrm{O}_{3}$ powder, $98 \%$ purity, mean size: $45 \mu \mathrm{m}$ (325 mesh); $\mathrm{Fe}_{3} \mathrm{O}_{4}$ powder (Kojyundo Chemical Laboratory, Japan), mean size: $1 \mu \mathrm{m}$; and iron powder (Kojyundo Chemical Laboratory, Japan), mean size: below $5 \mu \mathrm{m}$. Since the metal oxides are small, it is supposed that the size of the powder $n$ in the case of laser ablation in liquids is submicron.

Experimental setups based on laser ablation in liquid to reduce metal-oxide powders are shown in Figure 3. The experimental setup based on the laser ablation in liquid to reduce $\mathrm{Fe}_{2} \mathrm{O}_{3}$ powders using a low-repetition Nd:YAG pulsed laser (Surelite II SLI-10 Continuum; wavelength: $1064 \mathrm{~nm}$; pulse duration: $8 \mathrm{~ns}$; repetition frequency: $10 \mathrm{~Hz}$ ) is shown in Figure 3(a). The diameter of the output laser beam was $6 \mathrm{~mm}\left(\mathrm{e}^{-2}\right)$. A pear-shaped silicon-glass bottle was used to reduce the $\mathrm{Fe}_{2} \mathrm{O}_{3}$ powders. Laser pulses are entered to a mirror in the horizontal direction, and they change direction to the vertical direction under the glass bottle. The laser pulses were irradiated on the bottom of the glass bottle. About $4 \%$ of the irradiated laser energy was reflected on the surface of the bottle by the Fresnel reflection. The laser pulses were focused in the acetone liquid at a distance of $15 \mathrm{~mm}$ from the bottom of the glass bottle. The quantity of acetone in the bottle was $30 \mathrm{~mL}$. Oxygen in the acetone was removed by 


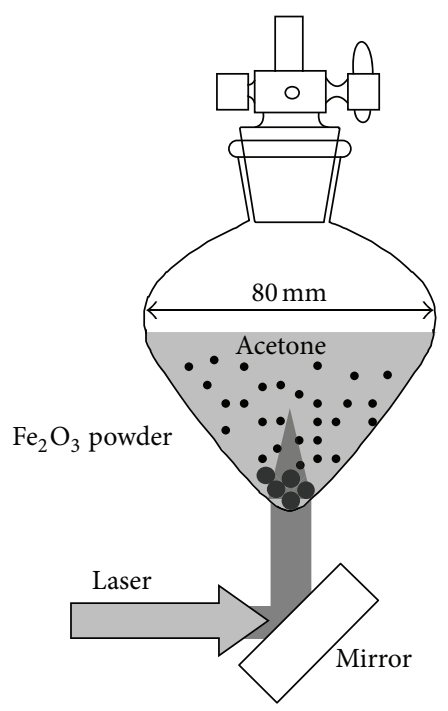

(a)

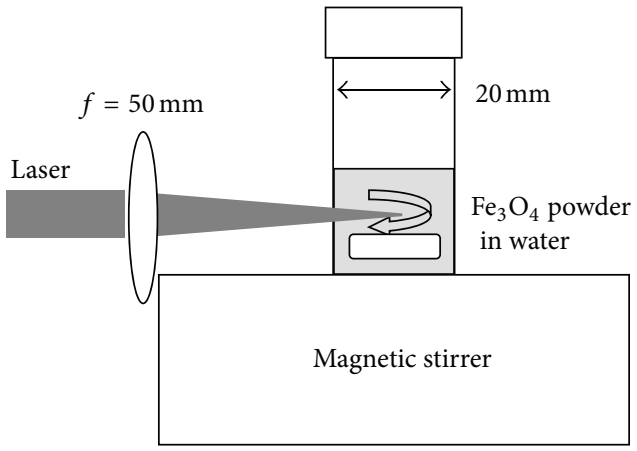

(b)

Figure 3: Experimental setup for laser ablation in liquid. (a) Reducing $\mathrm{Fe}_{2} \mathrm{O}_{3}$ powder with 10-Hz Nd:YAG pulsed laser, and (b) reducing $\mathrm{Fe}_{3} \mathrm{O}_{4}$ powder with high-repetition-rate Nd:YAG pulsed laser.

using argon for eight minutes. Here, the irradiation fluence was evaluated to be more than $20 \mathrm{~J} / \mathrm{cm}^{2}$. Free convection was thus generated in the glass bottle. The effect is the same as that caused by the mixing. The irradiation time was 20 minutes. To obtain reduced $50 \mathrm{mg}$ of iron nanoparticles, the reduction experiment was repeated 14 times. The total weight of the $\mathrm{Fe}_{2} \mathrm{O}_{3}$ powder used was $70 \mathrm{mg}$.

The experimental setup based on laser ablation in liquid to reduce $\mathrm{Fe}_{3} \mathrm{O}_{4}$ powders by using a high-repetition Nd:YAG pulsed laser is shown in Figure 3(b). In this study, we used high-repetition microchip Nd:YAG pulsed laser. Maximum output-averaged laser power was $250 \mathrm{~mW}$, laser wavelength was $1064 \mathrm{~nm}$, repetition rate of the laser pulses was $18 \mathrm{kHz}$, and pulse duration was $8 \mathrm{~ns}$. A beam with a diameter of $6 \mathrm{~mm}\left(1 / \mathrm{e}^{2}\right)$ was focused by using a lens with a focal length of $50 \mathrm{~mm}$. The diameter of the focused beam was thus $20 \mu \mathrm{m}$ at the front of each glass bottle. Glass bottles with a diameter of $20 \mathrm{~mm} \Phi$ and length of $38 \mathrm{mmL}$ were used in the experiment. $100 \mathrm{mg}$ of $\mathrm{Fe}_{3} \mathrm{O}_{4}$ was confined in the glass bottles with $5 \mathrm{~mL}$ of pure water and stirred. The water was mixed by magnetic stirrer (rotation velocity: $1200 \mathrm{rpm}$ ) during laser pulses irradiation. Laser pulses were irradiated to the water with the metal oxides in glass bottle for 10 minutes. Here, the fluence of the irradiated laser pulse was estimated to be $4.5 \mathrm{~J} / \mathrm{cm}^{2}$. After laser irradiation, the water was removed from the glass bottle, and the powder was dried. This process was repeated five times. The reduced powder was collected, and a part of all the reduced iron nanoparticles with the weight of $100 \mathrm{mg}$ was picked up and measured. The reduced iron nanoparticles were used for the hydrogen production.

Fluence $\left(\mathrm{J} / \mathrm{cm}^{2}\right)$ and the intensity $\left(\mathrm{W} / \mathrm{cm}^{2}\right)$ of the irradiating laser pulses are important for reducing metal oxides by laser ablation in liquids. The fluence must be adequately more than $0.1 \mathrm{~J} / \mathrm{cm}^{2}$ to heat the metal-oxide particles to a high temperature over their melting point, and the intensity must be over sub $0.1 \mathrm{GW} / \mathrm{cm}^{2}$ due to induction of avalanche ionization and extraction of electrons from the metal oxides.

The conditions for the irradiation intensity of the laser pulses and the high absorption coefficient are adequate for reducing $\mathrm{Fe}_{3} \mathrm{O}_{4}$ powders. However, for reducing $\mathrm{Fe}_{2} \mathrm{O}_{3}$ by using the high-repetition Nd:YAG pulsed laser, the absorption coefficient at $1064 \mathrm{~nm}$ wavelength is low, the irradiation intensity and fluence are low, and it has been found that the reduction of $\mathrm{Fe}_{2} \mathrm{O}_{3}$ using a high-repetition Nd:YAG pulsed laser is hard. Accordingly, in this study, a lowrepetition Nd:YAG pulsed laser was used for reducing the $\mathrm{Fe}_{2} \mathrm{O}_{3}$ powder. Additionally, it has already been found in our experiments that the $\mathrm{Fe}_{3} \mathrm{O}_{4}$ powders can be reduced by using this low-repetition Nd:YAG pulsed laser.

Analysis of crystal structure by X-ray Diffraction (XRD) (MAXima_X XRD-7000, Shimadzu, Japan) was performed to check the quantities of iron in the $\mathrm{Fe}_{3} \mathrm{O}_{4}$ powders irradiated by the high-repetition Nd:YAG pulsed laser. K- $\alpha$ X-ray radiation of copper was irradiated onto the samples.

2.2. Hydrogen Production. The method used for hydrogen production is described in the following. The chemical formula for reacting $\mathrm{Fe}_{3} \mathrm{O}_{4}$ powders with vaporized water is given as

$$
\begin{array}{r}
\mathrm{Fe}_{3} \mathrm{O}_{4}(\mathrm{~s})+\frac{1}{2} \mathrm{H}_{2} \mathrm{O}(\mathrm{g}) \longrightarrow \frac{3}{2} \mathrm{Fe}_{2} \mathrm{O}_{3}(\mathrm{~s})+\frac{1}{2} \mathrm{H}_{2}(\mathrm{~g}), \\
\Delta H=364.8 \mathrm{~kJ} / \mathrm{mol} .
\end{array}
$$

And the chemical formula for reacting iron powders with vaporized water is given as

$$
\begin{array}{r}
\mathrm{Fe}(\mathrm{s})+\frac{4}{3} \mathrm{H}_{2} \mathrm{O}(\mathrm{g}) \longrightarrow \frac{1}{3} \mathrm{Fe}_{3} \mathrm{O}_{4}(\mathrm{~s})+\frac{4}{3} \mathrm{H}_{2}(\mathrm{~g}), \\
\Delta H=-50.6 \mathrm{~kJ} / \mathrm{mol} .
\end{array}
$$




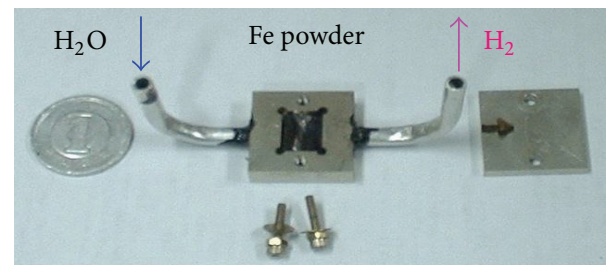

(a)

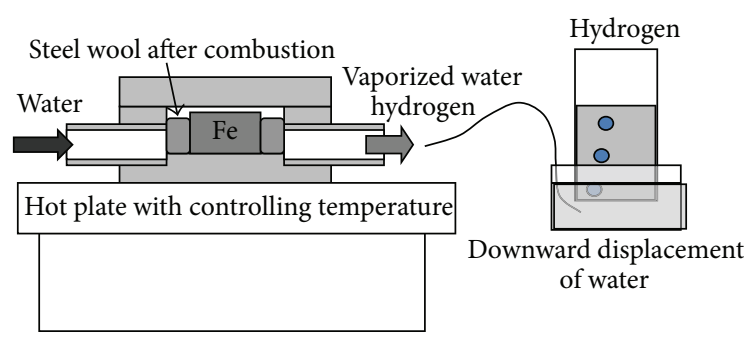

(b)

FIGURE 4: Hydrogen production: (a) photo of instrument for hydrogen production and (b) experimental setup.

In (3), the enthalpy energy is for per unit mol Fe to react with vaporized water. In the reaction of $\mathrm{Fe}_{3} \mathrm{O}_{4}$ with water, the water must be at high temperature and vaporized. The reaction of $\mathrm{Fe}_{3} \mathrm{O}_{4}$ with water is endothermic, and the reaction of iron with water is exothermic. It is clear that a certain amount of energy, which is required for reducing metal oxide, is needed for reacting $\mathrm{Fe}_{3} \mathrm{O}_{4}$ with water. Thus, the reaction for hydrogen production using $\mathrm{Fe}_{3} \mathrm{O}_{4}$ powder is difficult at $673 \mathrm{~K}$. Equation (4) shows that $12 \%$ of the stored potential energy when the metal oxide was reduced is wasted as heat. The experimental setup for generating hydrogen is shown in Figure 4. A photo of the reaction container is shown in Figure 4(a), and experimental setup for generating hydrogen is shown in Figure 4(b). The outer size of the aluminum container was $20 \times 20 \mathrm{~mm}^{2} \times 9 \mathrm{mmt}$, and the container is solid and does not react with pure water at up to $973 \mathrm{~K}$. The inner size of the aluminum container was 5 $\times 8 \mathrm{~mm}^{2} \times 3 \mathrm{mmt}$. The center of the device was placed on the reduced iron nanoparticles placed on an aluminum-foil sheet, and steel wool was set between the container and the right aluminum tube to prevent outflow of the powder. The aluminum container was heated in the range of 523 to $673 \mathrm{~K}$ by hot plate (CHP-170AN, Asone, Japan). Pure water at a temperature of $295 \mathrm{~K}$ was injected into the container from the left aluminum tube. Once the water was absorbed, the steel wool combusted, and the water was vaporized and reacted with the iron powder. After the reaction, hydrogen was extracted from the right aluminum tube. The generated hydrogen was collected by the water-replacement method. The generated hydrogen was gathered in a silicon glass bottle.

When iron nanoparticles were used for hydrogen production, it was necessary to heat them. Compared with these results using reduced Fe nanoparticles, micron-diameter iron powder with a weight of $100 \mathrm{mg}$ irradiated laser pulses was used for the hydrogen production. The reduction process was repeated 10 times. The synthesized iron nanoparticles were also used for the hydrogen production.

\section{Results}

3.1. Reduced Iron Nanoparticles from Iron Oxides. The XRD analysis shows that the iron nanoparticles have a lot of $\gamma \mathrm{Fe}$. The results of analyzing iron powders by XRD are shown in Figure 5. In common cases, determining the quantity of iron was difficult because the peak spectrum of $\mathrm{Fe}_{3} \mathrm{O}_{4}$ is

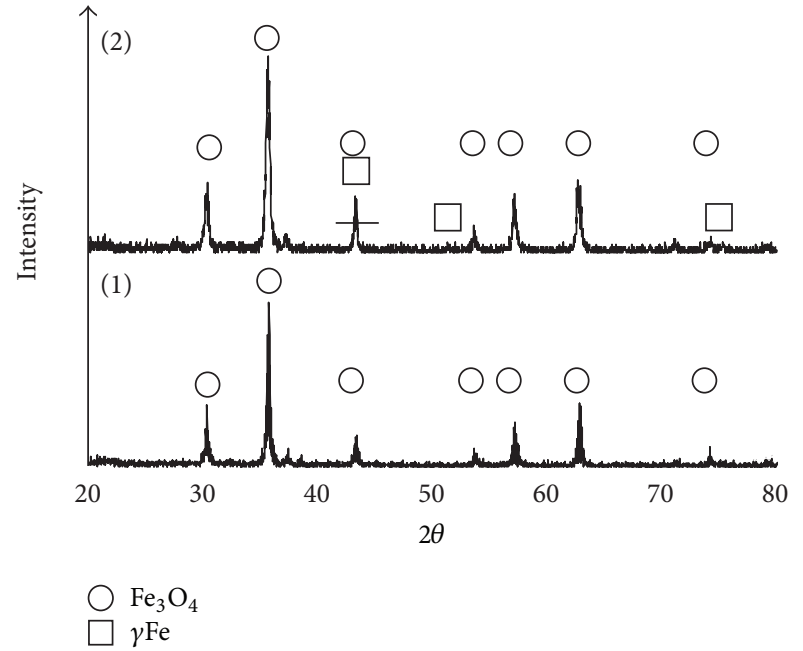

FIgURE 5: Results of analyzed $\mathrm{Fe}_{3} \mathrm{O}_{4}$ powder and reduced iron nanoparticles by XRD. (1) $\mathrm{Fe}_{3} \mathrm{O}_{4}$ powder and (2) $\mathrm{Fe}_{3} \mathrm{O}_{4}$ powder after irradiating laser pulses.

larger than that of $\alpha \mathrm{Fe}$ or $\gamma \mathrm{Fe}$ at the same quantity. Two components of $\gamma \mathrm{Fe}$, at angles of 42.8 and 75 degrees, can be seen in Figure 5. The $\gamma \mathrm{Fe}$ component was clearly recognized. The spectrum peak of iron at 42.8 degrees was evaluated by extracting the $\mathrm{Fe}_{3} \mathrm{O}_{4}$ component and is nearly as high as that of $\mathrm{Fe}_{3} \mathrm{O}_{4}$ at 43.1 degrees. Thus, the reduced iron nanoparticles contain a large quantity of $\gamma \mathrm{Fe}$ but a negligible quantity of $\mathrm{Fe}_{3} \mathrm{O}_{4}$. In the common case, the $\alpha \mathrm{Fe}$ and $\mathrm{Fe}_{3} \mathrm{O}_{4}$ components are recognized at angles of 44.7 and 43.1 degrees. The $\alpha \mathrm{Fe}$ component is normally observed. However, it has been already reported that when a CW laser or a pulsed laser was used to heat the surface of a stainless plate, $\alpha \mathrm{Fe}$ is changed to $\gamma \mathrm{Fe}$ by a high temperature generated by laser [19].

As for $\mathrm{Fe}_{2} \mathrm{O}_{3}$ reduction, it is easy to judge the state of iron oxides by their color when laser irradiation was conducted. The color of the $\mathrm{Fe}_{2} \mathrm{O}_{3}$ in the glass bottle changed from red to black. And some reduced iron nanoparticles became glossy. The color of the iron was silvery-white. As for $\mathrm{Fe}_{3} \mathrm{O}_{4}$ reductions, when the reduced iron was observed, the color of a few iron particles was gray, and most of the remaining powder was black. However, inside the reduced iron was pure iron, and only the outside of the reduced iron was oxidized. The mean size of the produced iron nanoparticles 


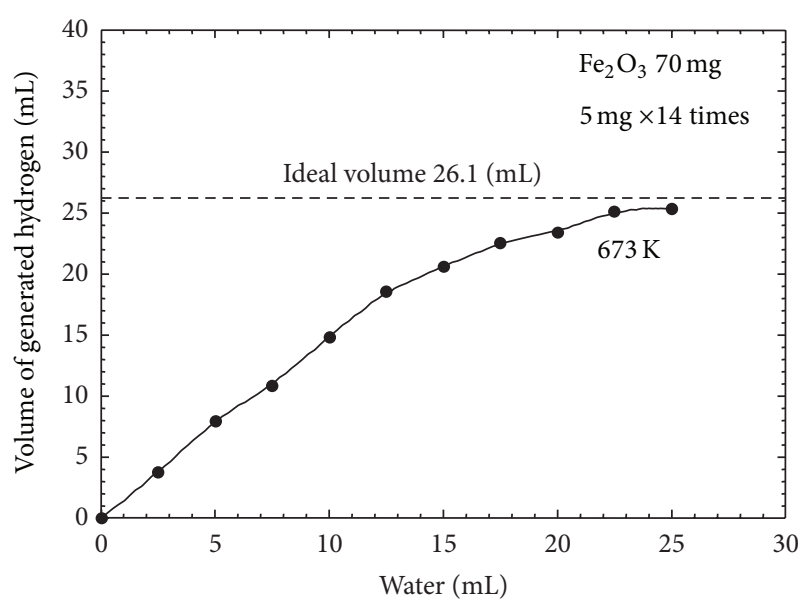

Figure 6: Hydrogen generated by using $\mathrm{Fe}_{2} \mathrm{O}_{3}$ after laser-pulse irradiation.

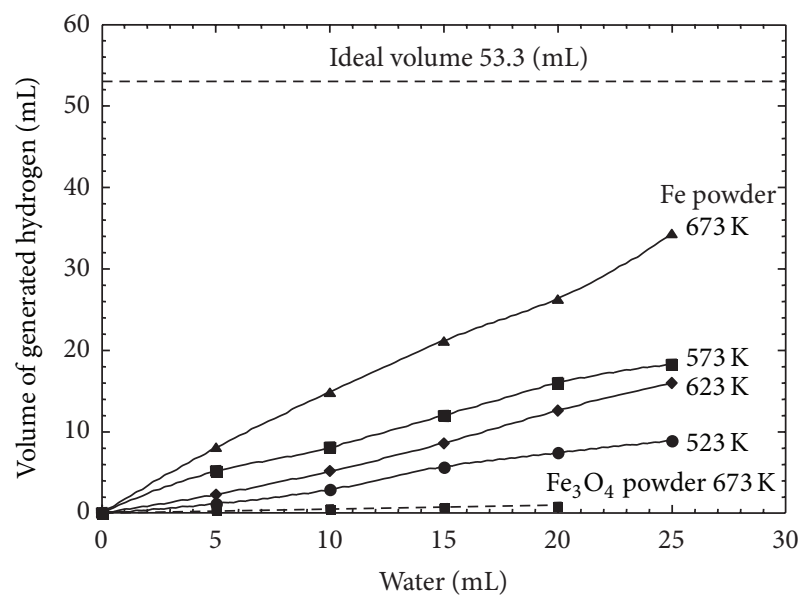

FIGURE 7: Hydrogen production using pure iron powder.

was measured by a particle-size analyzer to be a mean size in the order of $20 \mathrm{~nm}$.

3.2. Hydrogen Production. Density of generated hydrogen was measured by a hydrogen meter (Finch-Mono II, Japan). The obtained hydrogen was diluted once with $500 \mathrm{~mL}$ air, and the density was measured. The density of the hydrogen was compared with that of the hydrogen produced by electrolysis. It was thereby confirmed that the hydrogen concentration was near $99 \%$ and almost the same as that produced by electrolysis.

Hydrogen production was conducted using reduced iron nanoparticles from $\mathrm{Fe}_{2} \mathrm{O}_{3}$ powder. The experimental results are shown in Figure 6 . The instrument for producing hydrogen was heated by the hot plate at up to $673 \mathrm{~K}$. About $25 \mathrm{~mL}$ of hydrogen was obtained, when the instrument was heated at $673 \mathrm{~K}$. The theoretical volume needed for generating hydrogen using $50 \mathrm{mg}$ of iron nanoparticles was $26.1 \mathrm{~mL}$, when all of the $\mathrm{Fe}_{2} \mathrm{O}_{3}$ particles (with the weight of $70 \mathrm{mg}$ ) were reduced. The maximum reaction efficiency using reduced

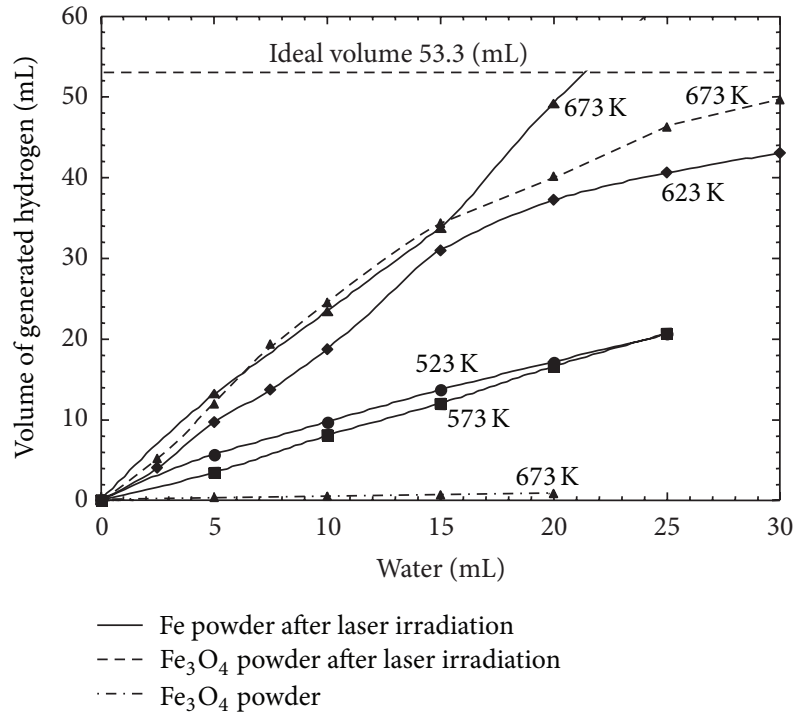

FIgURE 8: Hydrogen production using pure iron and $\mathrm{Fe}_{3} \mathrm{O}_{4}$ powder after laser-pulse irradiation.

iron nanoparticles from $\mathrm{Fe}_{2} \mathrm{O}_{3}$ powder was evaluated to be $96 \%$ from the experimental result.

Hydrogen production was produced by using $100 \mathrm{mg}$ of pure iron powder in the reactor. The experimental results are shown in Figure 7. The reactor was heated at 523, 573, 623, and $673 \mathrm{~K}$, and $25 \mathrm{~mL}$ of water was used. Most of hydrogen $(35 \mathrm{~mL})$ was obtained when the temperature of the heated reactor was at $673 \mathrm{~K}$. The theoretical volume to generate hydrogen using iron powder with a weight of $100 \mathrm{mg}$ is $53.3 \mathrm{~mL}$. The maximum volume of hydrogen was generated at $673 \mathrm{~K}$, and the reaction efficiency for hydrogen generation was evaluated to be $66 \%$, while less than $0.3 \mathrm{~mL}$ of hydrogen was obtained using $\mathrm{Fe}_{3} \mathrm{O}_{4}$ particles with the mean size of $1 \mu \mathrm{m}$, when the instrument was heated at $673 \mathrm{~K}$.

Hydrogen production was conducted using iron nanoparticles (with a weight of $100 \mathrm{mg}$ ) made from pure iron powder irradiated by a high-repetition-rate microchip Nd:YAG pulsed laser in water. The experimental results are shown in Figure 8. The reactor was also heated at 523, 573 , and $673 \mathrm{~K}$. The amount of water used was $20 \mathrm{~mL}$. The maximum volume of generated hydrogen was $50 \mathrm{~mL}$ at reactor temperature of $673 \mathrm{~K}$. The reaction efficiency for hydrogen generation was evaluated as about 94\%. The theoretical volume of hydrogen that can be generated is $53.3 \mathrm{~mL}$. It has been found that the reaction speed and efficiency using iron powder irradiated by laser pulses were improved because the mean size of the iron powder became $10 \mathrm{~nm}$ order, and the surface area of reacting iron particles increased. A maximum amount of hydrogen was also observed at $673 \mathrm{~K}$.

Finally, hydrogen production was conducted using reduced iron nanoparticles (with a weight of $100 \mathrm{mg}$ ) from $\mathrm{Fe}_{3} \mathrm{O}_{4}$ powder irradiated by the high-repetition-rate microchip Nd:YAG pulsed laser in liquid. The reactor was heated at 523, 573, 623 and $673 \mathrm{~K}$, and $25 \mathrm{~mL}$ of pure water 
was used. The experimental results are shown in Figure 8. The maximum amount of hydrogen obtained was $50 \mathrm{~mL}$, when the temperature of the reactor was $673 \mathrm{~K}$. The reaction efficiency of the hydrogen generation was evaluated to be $94 \%$ for a theoretical volume of generated hydrogen of $53.3 \mathrm{~mL}$.

\section{Discussion}

$\mathrm{Fe}_{2} \mathrm{O}_{3}, \mathrm{Fe}_{3} \mathrm{O}_{4}$, and iron powders were reduced by using laser ablation in liquid. Iron oxide was chosen as a metal oxide for the energy cycle because the Clarke number was the third, and the iron amount in recoverable reserves, which could be mined economically and technically, is about 10 times that of aluminum oxide. Iron is easy to obtain and use.

We discuss the absorption of laser pulses to metal oxides. The absorption process of a laser pulse by metal oxides has two possibilities: normal linear absorption and multiphoton absorption. In this experiment, in laser ablation in liquids, the latter mainly occurs. Smaller particles make electrons in the metal oxides more active, and electron emission will thus occur actively. The absorption coefficients of $\mathrm{Fe}_{2} \mathrm{O}_{3}$ and $\mathrm{Fe}_{3} \mathrm{O}_{4}$ are markedly different. $\mathrm{Fe}_{3} \mathrm{O}_{4}$ powder should be used for the energy recycle because its absorption coefficient at $1064 \mathrm{~nm}$ wavelength is high, and after producing hydrogen, $\mathrm{Fe}_{3} \mathrm{O}_{4}$ powders are mainly produced.

If a CW laser is used for reduction of the metal oxides, the reduction efficiency will be low because the generated temperature of the metal oxides is low. The CW laser has a low peak power, and it cannot heat the metal oxides up to a melting temperature in a short time. Moreover, the low intensity results in no avalanche ionization and less electron ejection.

The coulomb explosion and thermal ablation had been proposed as the ablation mechanism of the metal oxide in the liquid. The coulomb explosion was mainly considered in this study. It has been suggested that metal-oxide particles are broken into pieces in the Coulomb explosion. Firstly, the metal oxide is heated to over its melting temperature, at which it changes to form a gel. Electrons in the atoms of the metal oxide are ejected by the intense electric field of the irradiated laser pulses. After the particles become positively charged, the metal oxides repel each other by the same positive charge. Finally, a plasma is produced and atomized. In the case of using water for laser ablation, a subreaction occurs. In the coulomb explosion, the ejected electrons and oxide atom react with the water, and $\mathrm{OH}^{-}$ions are generated. As a result, the water becomes alkaline. This phenomenon had already been observed in some experiments.

Two lasers, high- and low-repetition-rate $\mathrm{Nd}$ :YAG pulsed lasers, were used to reduce $\mathrm{Fe}_{2} \mathrm{O}_{3}$ and $\mathrm{Fe}_{3} \mathrm{O}_{4}$ by laser ablation in liquid. It was found that the high-repetitionrate laser attained higher reduction efficiency than the lowrepetition-rate laser. The reduction efficiency of the metal oxides generated by using the high-repetition laser pulses was higher than that for the low-repetition pulsed laser for the same averaged laser power. The reduction efficiency will depend on the interaction time between the metal oxides and laser pulses. The emission time of electrons should be determined by a single factor, namely, multiplication of pulse duration and repetitive rate. Thus, it will be possible to reduce $100 \mathrm{mg}$ of metal oxides in less than 10 minutes by using a high-repetition-pulse laser. Moreover, metal with more than $200 \mathrm{mg}$ of oxides can be reduced in 10 minutes. Reduction of metal oxide will occur in single laser pulse.

We conducted hydrogen production by using small instrument for hydrogen production and the reduced iron. Hydrogen was produced by using a small instrument and the reduced iron. As a consequence, the obtained reaction efficiency of hydrogen generation using iron nanoparticles reduced by laser pulses was $94 \%$, which is high enough in the case that the particles have oxide shells. It means that the reduction of the metal particles by laser ablation in liquids was almost complete. Moreover, power generation in the hydrogen fuel cell was confirmed.

If the particle sizes of the iron nanoparticles were less than $10 \mathrm{~nm}$, it is predicted that iron nanoparticles will react with water completely by heating the temperature of the instrument for hydrogen production to be close to $373 \mathrm{~K}$.

For producing hydrogen using iron nanoparticles reduced from $\mathrm{Fe}_{3} \mathrm{O}_{4}$, a dispersing agent for protecting the condensed nanoparticles is commonly used. An agent was not used in the present study because the condensation should not affect the reaction efficiency. In the case of using water for producing hydrogen, the surfaces of the produced iron nanoparticles are oxidized. However, the oxide surface did not affect the reaction efficiency of hydrogen production.

An energy loss occurs in the process of producing hydrogen for the produced iron nanoparticles. The energy loss is one eighth of the stored energy in the iron nanoparticles as the difference of the potential energy between iron oxides and iron in the reducing process. It is small and converts to heat. However, only $43 \mathrm{mg}$ of water is needed to react with $100 \mathrm{mg}$ of pure iron. In this experiment, the weight of the water used was $25 \mathrm{~g}$. Thus, a lot of water was wasted without reacting with the iron nanoparticles. To eliminate this waste, first, the water should be confined in the reactor to improve the reaction efficiency with iron nanoparticles. Second, the reaction efficiency of the iron nanoparticles should be suppressed to $90 \%$ because the production rate of hydrogen degrades remarkably. It introduces to save the required water and electricity to heat and to recycle efficiently.

Solar energy or other natural energies are considered as sources of laser power for laser ablation in liquid. However, the most suitable lasers for energy cycles are considered to be solar-pumped lasers because common lasers have low electro-optical conversion efficiency.

In the future, we will establish a clean-energy hydrogenproduction cycle that is simple, low-cost, no-carbon, and recyclable by combining a solar-pumped laser and laser ablation.

\section{Conclusion}

$\mathrm{Fe}_{2} \mathrm{O}_{3}$ and $\mathrm{Fe}_{3} \mathrm{O}_{4}$ powders were reduced with high efficiency by $\mathrm{Nd}$ :YAG pulsed lasers based on laser ablation in liquids. It was experimentally demonstrated that the produced iron 
nanoparticles can be used for hydrogen generation in an energy cycle. For hydrogen production using the reduced iron nanoparticles, the reaction efficiency of the hydrogen generation at a temperature of $673 \mathrm{~K}$ was more than $94 \%$ for the theoretically ideal amount of generated hydrogen. $\mathrm{Fe}_{3} \mathrm{O}_{4}$ powders remain after the hydrogen is produced, and they should be reduced by pulsed laser. Iron nanoparticles are reproduced and used for producing hydrogen again.

The laser pulses should be generated using a natural energy source, such as solar power or wind power. Furthermore, the laser pulses can be generated directly from solar light by using solar-pumped lasers. It has been expected that our proposed energy cycle by using pulsed laser and the Fe nanoparticles will be realized. The proposed energy cycle using a pulsed laser and iron nanoparticles is expected to provide simple, low-cost, and no-carbon production of recyclable hydrogen.

\section{References}

[1] P. Charvin, S. Abanades, F. Lemort, and G. Flamant, "Hydrogen production by three-step solar thermochemical cycles using hydroxides and metal oxide systems," Energy and Fuels, vol. 21, no. 5, pp. 2919-2928, 2007.

[2] M. S. Mohamed, T. Yabe, C. Baasandash et al., "Laser-induced magnesium production from magnesium oxide using reducing agents," Journal of Applied Physics, vol. 104, no. 11, Article ID 113110, 2008.

[3] M. Uda, H. Okuyama, T. Suzuki, and Y. Yamada, "Hydrogen generation from water using $\mathrm{Mg}$ nanopowder produced by arc plasma method," Science and Technology of Advanced Materials, vol. 13, Article ID 025009, 2012.

[4] X. Jiang, M. Watanabe, H. Onishi, and R. Saito, "Applications of recycled materials to fuel cell and related technologies," Transactions of the Materials Research Society of Japan, vol. 29, no. 5, pp. 2507-2510, 2004 (Japanese).

[5] P. B. Tarman and D. V. Punwani, "Hydrogen production by the steam-iron process," in Proceedings of the 14th Intersociety Energy Conversion Engineering Conference, vol. 11, pp. 286-293, 1976.

[6] K. Otsuka, T. Kaburagi, C. Yamada, and S. Takenaka, "Chemical storage of hydrogen by modified iron oxides," Journal of Power Sources, vol. 122, no. 2, pp. 111-121, 2003.

[7] A. Henglein, "Physicochemical properties of small metal particles in solution: "microelectrode" reactions, chemisorption, composite metal particles, and the atom-to-metal transition," The Journal of Physical Chemistry B, vol. 97, pp. 5457-5471, 1993.

[8] M. S. Sibbald, G. humanov, and T. M. Cotton, "Reduction of cytochrome c by halide-modified, laser-ablated silver colloids," The Journal of Physical Chemistry B, vol. 100, pp. 4672-4678, 1996.

[9] M. Kawasaki and N. Nishimura, "Laser-induced fragmentative decomposition of ketone-suspended $\mathrm{Ag} 2 \mathrm{O}$ micropowders to novel self-stabilized Ag nanoparticles," Journal of Physical Chemistry C, vol. 112, no. 40, pp. 15647-15655, 2008.

[10] H. Wang, A. Pyatenko, K. Kawaguchi, X. Li, Z. SwiatkowskaWarkocka, and N. Koshizaki, "Selective pulsed heating for the synthesis of semiconductor and metal submicrometer spheres," Angewandte Chemie, vol. 49, no. 36, pp. 6361-6364, 2010.

[11] S. Taniguchi, T. Saiki, T. Okada, and T. Furu, "Synthesis of reactive metal nanoparticles by laser ablation in liquids and its applications," in Proceedings of the 421th Topical Meeting of The Laser Society of Japan, Laser Technology for 21st Century, RTM11-56, pp. 25-30, 2011.

[12] V. Amendola, P. Riello, and M. Meneghetti, "Magnetic nanoparticles of iron carbide, iron oxide, iron@iron oxide, and metal iron synthesized by laser ablation in organic solvents," Journal of Physical Chemistry C, vol. 115, no. 12, pp. 5140-5146, 2011.

[13] T. Okada, S. Taniguchi, T. Saiki, T. Furu, K. Y. Iida, and M. Nakatsuka, "Synthesis of $\mathrm{Fe}$ and $\mathrm{FeO}$ nanoparticles by laser ablation in liquids and its applications," in Proceedings of the the 1st Advanced Lasers and Photon Sources, pp. 81-82, 2012.

[14] J. Purnell, E. M. Snyder, S. Wei, and A. W. Castleman Jr., "Ultrafast laser induced coulomb explosion of clusters with high charge states," Chemical Physics Letters, vol. 229, pp. 333-339, 1994.

[15] K. Yamada, K. Miyajima, and F. Mafune, "Ionization of gold nanoparticles in solution by pulse laser excitation as studied by mass spectrometric detection of gold cluster ions," The Journal of Physical Chemistry C, vol. 111, Article ID 033401, 2007.

[16] T. Saiki, T. Okada, K. Nakamura, T. Karita, Y. Nishikawa, and Y. Iida, "Air cells using negative metal electrodes fabricated by sintering pastes with base metal nanoparticles for efficient utilization of solar energy," International Journal of Energy Science, vol. 2, no. 6, pp. 228-234, 2012.

[17] M. Weksler and J. Shwartz, "Solar-pumped solid-state lasers," IEEE Journal of Quantum Electronics, vol. 24, no. 6, pp. 12221228, 1988.

[18] T. Saiki, M. Nakatsuka, and K. Imasaki, "Highly efficient lasing action of $\mathrm{Nd}^{3+}$ - and $\mathrm{Cr}^{3+}$-doped yttrium aluminum garnet ceramics based on phonon-assisted cross-relaxation using solar light source," Japanese Journal of Applied Physics, vol. 49, no. 8, Article ID 082702, 2010.

[19] C. Cui, J. Hu, Y. Liu, K. Gao, and Z. Guo, "Morphological and structural characterizations of different oxides formed on the stainless steel by Nd:YAG pulsed laser irradiation," Applied Surface Science, vol. 254, no. 20, pp. 6537-6542, 2008. 


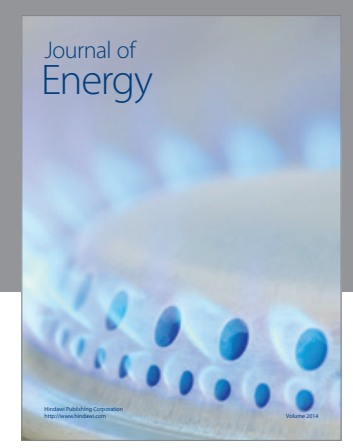

Journal of

Industrial Engineering
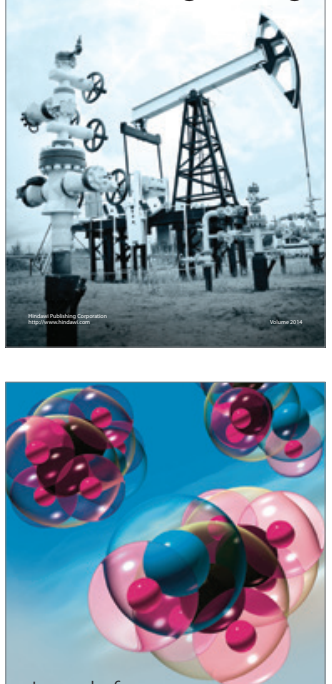

Fuels
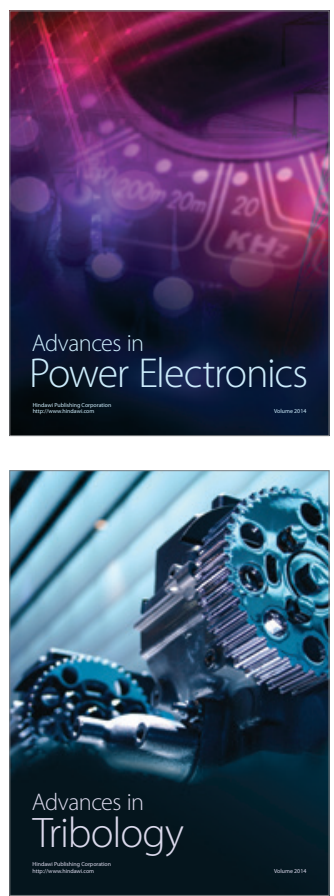

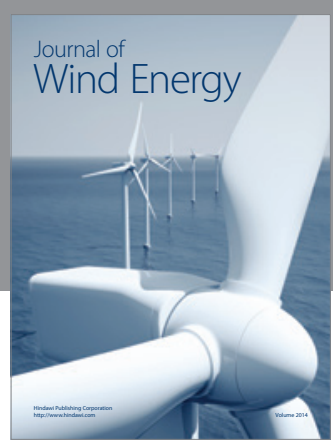

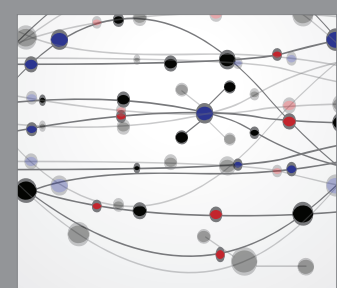

The Scientific World Journal

Submit your manuscripts at http://www.hindawi.com

Journal of

Structures
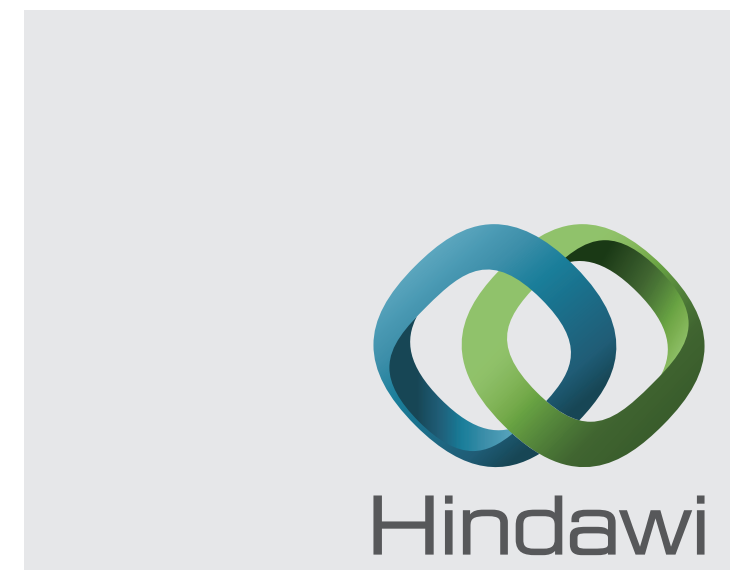

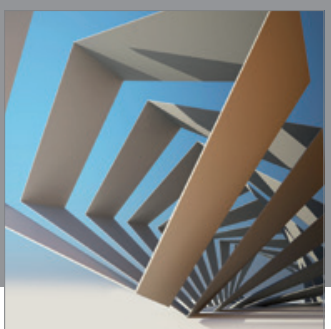

Rotating

Machinery
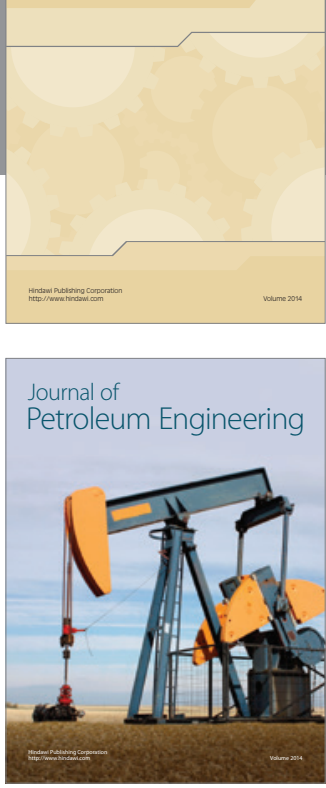

Journal of

Solar Energy
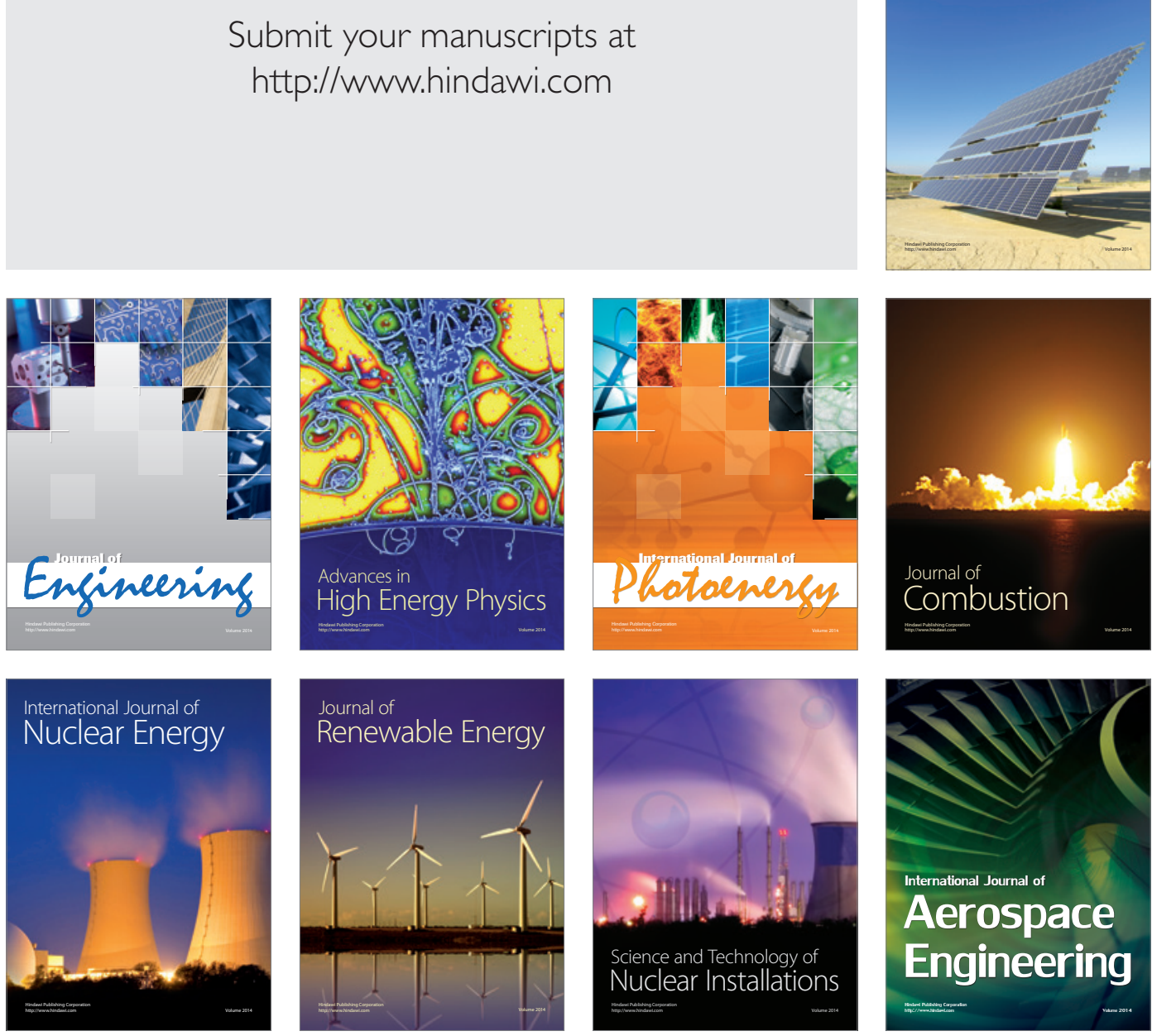